УДК $81 ` 25$

ББК 81.18

DOI: https://doi.org/10.17308/lic.2020.1/2729

\title{
СОХРАНЕНИЕ ЭКСПРЕССИВНОСТИ ПРИ ПЕРЕВОДЕ МЕТАФОРЫ В НАУЧНО-ПОПУЛЯРНОМ ТЕКСТЕ
}

\author{
И. Н. Яковлева, В. С. Колесникова \\ Воронежский государственный университет
}

\section{MAINTIANING EXPRESSIVNESS OF METAPHORS WHEN TRANSLATING POPULAR-SCIENTIFIC TEXT}

\author{
I. N. Yakovleva, V. S. Kolesnikova \\ Voronezh State University
}

\begin{abstract}
Аннотация: многочисленные труды, посвященные метафоре, преимущественно представляют собой аспектное описание феномена и не предлагают единого решения вопроса о ее происхождении и природе, а также, что более значимо для переводчика, наиболее эффективных способах перевода метафор с точки зрения сохранения их экспрессивности с учетом особенностей функционирования различных типов метафор в рамках научно-популярного текста, что обусловливает актуальность настоящего исследования. В статье определяется место научно-популярного текста в системе функциональных стилей и выделяются его значимые характеристики, необходимые для грамотного подбора текстов для анализа и формирования более полного представления о функичях метафор в рамках текстов данного типа. Также в статье рассматриваются возможные переводческие решения и трансформации и дается оценка их эффективности с точки зрения сохранения экспрессивности при переводе метафор в научно-популярных текстах с английского языка на русский, и наоборот. Результаты настоящего исследования могут лечь в основу теоретических работ, посвященных анализу состава метафор научно-популярного текста и анализу стратегий их перевода в научно-популярном подстиле. Выводы, сделанные в результате анализа многочисленных текстов и метафорических употреблений, могут помочь практикующим переводчикам избежать случаев нежелательного изменения экспрессивности в тексте перевода по сравнению с оригиналом и выбрать предпочтительные стратегии передачи метафор в научно-популярном тексте.
\end{abstract}

Ключевые слова: метафора, научно-популярный, перевод, трансформация, экспрессивность.

\begin{abstract}
: numerous works on metaphor mostly describe different aspects of the phenomenon rather than give answers about its origin or, which is more important for a translator, effective translation techniques necessary to maintain the level of expressiveness of different types of metaphors in a popular-scientific text. All the above determines the topicality of this research. The article specifies the place of a popular-scientific text among other types of texts, which is crucial for the selection of practical material and understanding of the functions of metaphors in this type of text. Also, the article focuses on possible translator choices and translation techniques which are assessed in the context of maintaining of expressiveness of metaphors translated both from English into Russian and from Russian into English. The results of this research can be used for the analyses of metaphors and their translations in a popular-scientific text. The arguments and findings can help translators avoid unnecessary lowering of the level of expressiveness.

Key words: metaphor, popular-scientific, translation, translation technique, expressiveness.
\end{abstract}

«Лингвистический энциклопедический словарь» под редакцией В. Н. Ярцевой предлагает определение, согласно которому «метафора (от греч. metaphora- перенос) - троп или механизм речи, состоящий в употреблении слова, обозначающего некоторый класс предметов, явлений и т. п., для характеризации или

(С) Яковлева И. Н., Колесникова В. С., 2020 
наименования объекта, входящего в другой класс, либо наименования другого класса объектов, аналогичного данному в каком-либо отношении» [1, с. 296]. Отмечается, что в самом широком понимании термин применяется для описания любого употребления слова в непрямом значении. Метафора характеризуется семантической двойственностью, что выражается в ассоциативной связи двух категорий объектов, не допускающей рассмотрение метафоры изолированно от определяемого [1, с. 296].

Ряд языковедов и литературоведов признают метафору стилистическим явлением, характерным для текстов художественных произведений и выполняющим преимущественно эстетическую функцию, и предлагают упрощенное определение метафоры, сводимое к понятию «скрытого сравнения» (М. Блэр, Дж. Рэнсом). Большая часть лингвистов относит ее к языковым явлениям (В. Н. Телия, Г. Н. Скляревская), однако все большее распространение получает точка зрения, представители которой причисляют метафору к механизмам сознания (Э. Маккормак, А. Ортони, Дж. Лакофф и М. Джонсон).

Выступая образной фигурой речи, метафора обогащает речь и добавляет ей выразительности, однако последние исследования из области когнитивистики доказывают, что наряду с признанием ее эстетической ценности, метафору следует рассматривать на более глубоком уровне и отнести к способам познания мира, и хотя метафора традиционно рассматривается в художественном тексте, нельзя игнорировать факт ее проникновения во все сферы человеческой деятельности, в частности в развивающийся в русском языке под сильным влиянием английского научно-популярный дискурс, который характеризуется особой метафоричностью.

Начало изучения научно-популярного текста было положено еще в XIX в. Д. И. Писаревым, который разработал принципы изложения данного стиля [2, c. 180-185].

Некоторые стилисты (Н. Н. Маевский, Г. А. Васюченко, М. К. Милых, Н. Я. Сердобинцев и др.) выделяют самостоятельный научно-популярный стиль, указывая на обилие научно-популярных публикаций и важность выполняемых ими функций, а также на складывание особого типа изложения, обусловленного особым отбором лексических и синтаксических средств [3], однако данная точка зрения получает меньшее распространение, чем признание научно-популярного текста вариантной разновидностью, или подстилем, научного стиля (М. Н. Кожина, И. Р. Гальперин, Р. А. Будагов, Т. А. Тимофеева, М. П. Сенкевич, Л. А. Баташева и др.) [2]. В то же время Н. М. Разинкина относит научно-популярную литературу к «межстилевому жанру» [4, с. 41].
Признать научный и научно-популярный тексты находящимся в родо-видовых отношениях позволяет наличие общей коммуникативной установки - передачи некоторого научного знания, при одновременном различии частных коммуникативных задач (передача научного знания специалисту для научного текста и передача научного знания неспециалисту в доступной форме - для научно-популярного), а также сфер функционирования таких текстов [2]. При популяризации научных текстов такие признаки научного стиля, как безличный, объективный и безэмоциональный характер сообщения, становятся вторичными [5, c. 7], однако не исчезают полностью, проявляясь на уровне лексики и синтаксиса. При этом в научно-популярных текстах ярче проявляется диалогичный характер изложения, так как очевидна установка на ответную реакцию читателя [2].

Согласно Т. И. Уткиной, становление научно-популярного дискурса определяется использованием следующих разнонаправленных когнитивно-коммуникативных стратегий: генерализации (предполагающей редукцию содержания, тематическое ограничение, а также снижение информационной плотности) и конкретизации (включающей в себя усложнение синтаксиса, усиление модальности изложения, создание образности и экспрессивности и персонификации) [6].

Лексическое наполнение текста данного типа, наряду с общеупотребительной и разговорной лексикой, содержит компоненты, присущие собственно научному стилю: общенаучную лексику, доля которой в сравнении с терминологией значительно выше, чем в научном тексте, а также термины, чаще общеупотребительные, а не узкоспециализированные, функционирование которых, однако, в результате адаптации несколько отлично от их функционирования в собственно научном тексте: стилистически нейтральный термин может приобретать в научно-популярном изложении эмоциональную окраску [5, с. 7], а наряду с принятыми в науке дефинициями типа «родовой признак» + «видовое отличие», в научно-популярной речи широкое распространение получили такие способы введения терминов, как краткая расшифровка их значения в скобках или сносках, разъяснение с помощью описательных оборотов, а также широкое использование примеров, сравнений и образных средств [2]. Согласно исследованиям в области современного научно-популярного стиля, необходимость в расширении читательской аудитории предполагает усиление экспрессивности текста с целью сделать его более увлекательным, что предполагает упрощение доказательной части и научного языка в зависимости от уровня подготовленности аудитории, а также широкое использование эпитетов, метафор, метонимий, олицетворений, гипербол, аллюзий и 
сравнений [7]. Отдельной значимостью среди средств образности, используемых в текстах научно-популярного подстиля, обладают метафоры.

Метафоричность является одной из отличительных черт научно-популярного подстиля. При этом функции метафор не ограничиваются созданием увлекательного художественного повествования, а преимущественно подчиняются необходимости проиллюстрировать описываемое явление, что перекликается с основной функцией метафоры вообще - когнитивной функцией.

Использование метафорических выражений способствует становлению и обогащению научно-популярного подстиля, однако справедливо и обратное ряд метафор создается непосредственно в рамках научно-популярного текста, что обогащает «метафорическую символику» языка в целом [3].

Основным источником образности научно-популярного текста являются общеязыковые, или стертые, метафоры (например, поток, волна, кольбель) [3]. Именно они формируют иллюстративную основу, применяясь преимущественно для объяснения, уточнения научного знания или проведения аналогии с другим.

Т. И. Уткина отмечает значимость функций метафор, соотносимых со стратегиями популяризации, в число которых включаются функции категоризации, контаминации, концептуализации, персонификации, а также положительного информирования [6]. На основании классификации В. К. Харченко к основным функциям метафоры в данном типе текста относятся объяснительная, эвристическая имнемоническая [8].

Метафора, являясь многоаспектным феноменом и выступая средством индивидуальной авторской оценки, представляет собой особую трудность для перевода.

Проблема перевода метафоры в различных типах текста занимает значимое место в трудах видных отечественных и зарубежных переводоведов (И. Р. Гальперин, В. Н. Вовк, В. Н. Комиссаров, Т. Р. Левицкая, П. Ньюмарк и др.).

Нами был проведен анализ метафорических употреблений на материале переводных научно-популярных статей с английского языка на русский и с русского на английский. Интерес в рамках исследования представляли переводческие стратегии, применяемые при передаче метафор на другой язык, а также их эффективность с точки зрения сохранения образа, лежащего в основе переноса, и экспрессивности выражения в целом.

В ходе работы над теоретическим и практическим материалом сложилась гипотеза, согласно которой метафоры в научно-популярных произведениях, написанных в оригинале на английском языке, обладают большей экспрессивностью, чем тексты на рус- ском языке, вследствие чего ожидается, что при переводе научно-популярных статей частотны случаи снижения экспрессивности.

Общий объем проанализированных метафорических употреблений составил 650 метафор в оригинальных и переводных текстах научно-популярных статей различной тематической направленности на английском и русском языках.

Способы перевода метафор рассматривались в рамках классификаций Я. И. Рецкера, Т. А. Казаковой и В. Н. Комиссарова. При этом в целях более полного анализа представленных переводческих решений мы объединили в одну категорию дублирующие друг друга типы (так, например, перевод калькированием у Я. И. Рецкера [9] и дословный перевод метафор у В. Н. Комиссарова [10] представлены в рамках настоящей статьи единой категорией «калькирование»). Использование трансформаций как способ перевода, представленный в классификации Я. И. Рецкера, как общая категория делится на конкретные типы трансформаций согласно классификации Т. А. Казаковой [11].

Так как метафоры в языке оригинала не всегда передаются метафорами в языке перевода, выбранные способы перевода учитывают как случаи сохранения образности, так и случаи ее нейтрализации. Случаи перевода метафоры метафорой классифицируются по следующим категориям: эквивалентное метафорическое соответствие, вариативное метафорическое соответствие, калькирование, перевод метафоры с сохранением и заменой оригинального образа, а также перевод с использованием трансформаций, в число которых включаются добавление и опущение элементов метафоры, лексическая замена, структурное преобразование и перевод метафор традиционным соответствием. Случаи перевода метафор неметафорами рассматриваются в рамках следующих категорий: эквивалентное и вариативное неметафорические соответствия, неметафорическое объяснение, перевод с использованием трансформаций.

Под эквивалентным метафорическим соответствием понимаются случаи перевода метафор, при котором метафоре в языке оригинала соответствует одна словарно закрепленная метафора в языке перевода, передающая тот же образ. Такие случаи чаще наблюдаются в сфере образной терминологии.

Так, например, очевидной образностью обладает выражение animal kingdom (представляющее собой перенос из сферы социальной жизни в сферу классификации животных), переводимое эквивалентным выражением царство животных, которое представляет собой закрепившуюся в русском языке кальку, полностью сохранившую образ оригинала.

Несколько иной случай представляет собой перешедшее в английский язык из латыни слово cortices, 
метафоричность которого в английском языке стерта, при переводе на русский язык эквивалентным термином кора возвращает образность латинского выражения. При этом, несмотря на ощутимую связь с первоначальным значением слова (перешедшим в сферу анатомии из сферы ботаники), подобная метафора не является художественным средством создания образности, а потому перевод метафоры с неощутимым образным компонентом выражением с ощутимой образностью является единственно допустимым вариантом ввиду учета функции метафоры, являющейся исключительно средством создания новой номинации.

Новая образная терминология, встречаемая в текстах астрономической, медицинской, психологической, экологической и ряда других тематик, преимущественно переходит в русский язык через английский, а потому образ оригинального выражения, как правило, сохраняется.

Так, в научно-популярных статьях о достижениях генной инженерии на русском языке встречается термин изепочка ДНК, являющийся словарно закрепленной калькой с английского выражения DNA chain, которым оно и переводится на английский язык. Несмотря на сохранение образности выражения в обоих языках, метафора по-прежнему является средством номинации, но не художественным средством.

Подобны предыдущему случаи перевода калькированием с полным сохранением исходного образа таких терминологических выражений, как вариативная звезда английским (и исходным) variable star, циклическая экономика-circular economy, генетический коктейль - genetic cocktail.

Под вариативным метафорическим соответствием понимаются случаи, когда метафоре на языке оригинала соответствуют несколько словарно закрепленных в языке перевода метафор, и переводчик выбирает одно из доступных соответствий.

Такие случаи более частотны. Так, например, в рассмотренных статьях на английском языке встречается выражение mislead, переводимое на русский язык метафорическими вариантами ввести в заблуждение, запутать и сбивать с толку. В основе разных вариантов перевода лежат неодинаковые, хотя и сходные, образы, однако в зависимости от выбранного эквивалента варьируется степень экспрессивности выражения, во многом определяемая в том числе и регистром - в том случае, если нейтральному выражению литературного регистра соответствует выражение просторечного или высокого регистра, или наоборот. Так, выражение mislead не обладает яркими коннотациями и носит нейтральный характер, в то время как сбивать с толку ближе к просторечию и потому более экспрессивно. Обратным примером повышения регистра является перевод выражения end uр метафорой обрести пристанище (в рассмотренных текстах также были зафиксированы вариативные неметафорические соответствия оказаться, nonacms, а также опущения). End up как фразовый глагол нейтрален, однако близок к просторечиям, в то время как обрести пристаншще относится к высокому регистру.

Для крайне частотной в текстах научно-популярного подстиля стертой метафоры discover в переводах на русский язык не обнаруживается единого эквивалента. В рассмотренных переводах фигурируют варианты обнаружить, открыть, вылснить и некоторые другие со сходным образом в основе, среди которых вариант открыть более явно обнаруживает связь со своим исходным неметафорическим значением.

Немного менее частотна в научно-популярных текстах на русском языке метафора открыть, преимущественно представленная в переводах на английский язык вариантами find и discover, в основе которых лежит сходный, но не точно сохраненный образ оригинального выражения.

В большинстве рассмотренных случаев переводные вариативные метафорические соответствия не обнаруживают существенных расхождений с выражениями оригинала в степени экспрессивности, а на их выбор, как и в художественном тексте, в ряде случаев влияет не только непосредственное окружение, но и более широкий контекст, исходя из которого переводчик прибегает к замене выражения синонимичным во избежание тавтологии, что может порождать случаи перевода одного выражения несколькими вариативными соответствиями в рамках одного текста (метафорическими или неметафорическими), как, например, в случае outdoors, переведенного в предложениях одного абзаца как под открытым небом и на просторах [Юты], оба из которых не характеризуются значительными колебаниями экспрессивности.

В то же время частотно встречаемая в статьях на русском языке метафора фиксировать [показания] передается в рассмотренных переводах вариативными соответствиями note и capture, последнее из которых обладает более ярким образом.

Эквивалентное неметафорическое соответствие в большинстве случаев предполагает перевод метафорического термина языка оригинала неметафорическим термином языка перевода.

Так, например, метафора head в названии должности head of the United Nations Environment Programme переводится в данном случае выражением исполнительный директор. Образность оригинала, хоть и стертая, при этом утрачивается, однако уровень экспрессивности предложения не обнаруживает существенных изменений, поскольку составная 
часть названия должности не является художественным средством, а используется исключительно в функции номинации.

Иным представляется случай перевода выражения freshman class выражением первый курс (несмотря на представленность в англо-русских словарях варианта перевода младший курс, данный случай рассматривается эквивалентным соответствием, так как младший курс имеет в русском языке более широкую референтную отнесенность, поскольку как первый, так и второй курс называются младшими). Ощутимая образность выражения в английском языке полностью снимается в переводе, что отражается на экспрессивности выражения в текстах оригинала и перевода. В качестве подтверждения того факта, что оригинальное выражение экспрессивно, его можно сравнить с синонимичным, но нейтральным выражением first year, также обозначающим первый курс обучения в высшем учебном заведении, однако намеренно не использованным автором.

В ходе исследования было обнаружено меньшее число примеров перевода метафоры неметафорическим эквивалентом с русского языка на английский, однако эти случаи также преимущественно связаны с переводом терминов.

Так, русский термин выделять [несколько белков] имеет метафорическое происхождение (согласно «Словарю русского языка» С. И. Ожегова, первое значение корня -дел- - отторгать часть целого, отделять), в то время как его английский эквивалент secrete имеет латинское происхождение и почти не обнаруживает связи с породившим его исходным значением, поскольку не имеет никакой другой референтной отнесенности, кроме обозначения выделения биологических жидкостей (в отличие от упомянутого paнее cortices, которое имеет несколько значений).

Случаи калькирования представляют собой буквальный перевод всех единиц, из которых состоит выражение оригинала.

Так, например, переводчики прибегают к калькированию живых авторских метафор: ocean Armageddonокеанский армагеддон; [the material is] not a housewife's friend - [материал] не является другом домохозяйки; colored plastic confetti - разноцветное пластиковое конфетти; планета-ад - hell planet. Ряд других случаев позволяет отнести калькирование к неоправданному буквализму (особенно заметному на уровне синтаксиса и сочетаемости: A world of possibilities opened up Mир новых возможностей открылся; we broke the system -мы сломали систему; давали высокую оценкуgave high assessment) или даже ошибке (возмущуения [в движении небесных тел] - indignation).

Случаи калькирования могут закрепляться в языке как эквивалентные способы перевода терминов или распространенных выражений, обладающих той же экспрессивностью, что и оригинальное выражение (in academic circles - в академических кругах, era of [material abundance] - эра [материального изобилия]).

Замена образа оригинала на сходный образ в переводе, как правило, обусловлена наличием в языке перевода закрепленной синонимичной метафоры с образом, более близким носителям культуры перевода (where do most of us draw the line - где проходum грань допустимого (образ нарисованной линии заменяется гранью, однако все еще явно предстает в виде некоей черты); put himself or herself in someone else's shoes - cтавить себя на чье-то место (несмотря на утрату в русском языке образа обуви, в которую становится человек, выражение обобщенно отражает идею перемещения на место, принадлежащее другому). Ряд случаев обнаруживает значительные расхождения в образной системе (who crunched the numbers - проводивших расчеты; mention in the same breath - обсуждать так же широко; разглядели - found, выдвинуть предположения - share assumptions).

Случаи неметафорического объяснения представляют собой перефразирование идеи, передаваемой с помощью метафоры в оригинале, с использованием неметафорических выражений в языке перевода.

Например, выражение that begs the question было переведено вариантом возник вопрос, который позволил переводчику избежать буквализма и доступно передать идею выражения, однако при этом была утрачена экспрессивная составляющая ярко окрашенного слова begs.

Выражение we are fed falsehoods также утратило эмоциональную составляющую при его переводе вариантом нам лгут люди, что, однако, ведет к экспликации смысла выражения в более широком контексте (подчеркивается идея того, что лжем не только мы, но и нам, при этом сосредоточенность на негативных эмоциях, передаваемых выражением в связи с этим, могла бы отвлечь читателя от главной идеи противопоставления).

Такая же тенденция отмечается при переводе метафорических выражений с русского на английский язык. Например, метафора гормональный коктейль (которую можно рассматривать как случай вторичного переноса названия) была переведена выражением complex of hormones, в результате чего утрачивается яркий образ напитка в основе оригинального выражения, но выражение приобретает более свойственный собственно научному стилю, нейтральный и безэмоциональный характер изложения.

Однако перевод метафоры неметафорическим объяснением не всегда ведет к заметному снижению экспрессивности выражения оригинала в тексте перевода.

Так, метафора breakthrough оказывается переведена неметафорическим выражением претенциозное 
исследование, что, хотя и происходит отказ от образности оригинального выражения, компенсируется добавлением слова претенциозное с яркой эмоциональной окраской.

Не все из проанализированных текстов получили полный перевод: в некоторых случаях переводчиками опускались фрагменты текста, которые содержали метафоры, однако и при сопоставлении переведенных фрагментов текста с оригиналом обнаруживается, что случаи опущения метафор частотны.

Например, в текстах перевода оказались опущены живые образные метафорические употребления Earth's last sink ("No one knows how much unrecycled plastic waste ends up in the ocean, Earth's last sink". "Неизвестно, сколько пластиковых отходов оказывается в Мировом океане”.); [academic science is] a world largely inhabited by people ("Even academic science - a world largely inhabited by people devoted to the pursuit of truth - has been shown to contain a rogues' gallery of deceivers " - “И даже среди ученьх, людей, казалось бы, посвятивших себя поиску правды, можно найти фальсификаторов"); [плато], очерченные множеством трешин ("На поверхности нашли так называемые «короны» - загадочные круглые плато, очерченные множеством трешин” - "The researchers found so-called "coronae" on the surface of Venus... they're largely circular features, hundreds to thousands of kilometres across, with an elevated bulge at the centre”) и ряд других.

Русский и английский языки обнаруживают существенные различия в синтаксисе, что является основной причиной использования трансформаций в переводе с целью экспликации значения исходного выражения. Среди трансформаций в исследуемых контекстах можно выделить приемы добавления и опущения элементов метафорического выражения, лексические замены, структурные преобразования и традиционные соответствия.

Так, перевод выражения is fundamental to us (coставное именное сказуемое) выражением глубоко сидит в нас (простое глагольное сказуемое) представляет собой пример структурного преобразования, необходимого по причине отсутствия в русском языке закрепившегося калькированного выражения со сходной структурой. Несмотря на структурные различия и проведенную замену образа, переводчику удается сохранить образность и даже усилить экспрессивность оригинального выражения.

Метафора [they] extend the life offresh food требует структурного преобразования, поскольку в русском языке отсутствует общепринятая идея о возможности продлить жизнь еды как неодушевленного предмета. Так, выполненный перевод имеет следующий вид: [упаковка] помогает сохранить продукты свежими. Несмотря на утрату исходной формы, перевод пол- ностью передает смысловое наполнение оригинала, а также включает метафору помогает, появление которой классифицировано как прием добавления. Добавление помогает сохранить метафорический характер выражения в целом и эксплицировать его смысл. С той же целью переводчиком применяется лексическая замена, в результате которой во фрагменте extend the life of слово extend (в значении расширять, продлевать) заменяется словом сохранить, что, однако, не искажает содержания исходного выражения. При проведении подобной замены слово life становится избыточным и опускается.

Под случаями традиционного соответствия нами понимаются примеры перевода устойчивого выражения в языке оригинала устойчивым выражением в языке перевода, при котором возможна значительная замена образа и оформления высказывания (be blinded [by a lie] - обвести вокруг пальца; найти пристанищуе, ban takes effect - запрет встуnаem в силу, play one's part [in the discovery] - внести свою лепту; с другой стороны - on the other hand). В подобных случаях наблюдается возможное варьирование регистра и, следовательно, экспрессивности.

Фокусом исследования способов перевода метафор был выбран эффект, производимый оригинальным и переводным фрагментом текста, описанный в терминах экспрессивности (которая понимается как производимый метафорой стилистический эффект: степень эмоциональности и психологической напряженности, вызываемой метафорическим выражением). Критерием эффективности способов перевода стало сохранение в переводе экспрессивности оригинального выражения.

Согласно полученным результатам, все рассмотренные способы перевода метафор с английского на русский язык носителями русского языка преимущественно сохраняют экспрессивность оригинального выражения или не обнаруживают существенного ее изменения. Подобное утверждение справедливо и для случаев номинативной метафоры, которая обладает нулевой экспрессивностью (нулевая экспрессивность остается нулевой в переводе).

Случаи усиления и снижения экспрессивности во многом оказались связаны с заменой метафорического выражения неметафорическим, а также заменой оригинального метафорического выражения с очевидной образностью выражением с менее яркой образностью в переводе, а также с заменой регистра речи: в подобных случаях наиболее распространенной оказалась замена нейтрального выражения разговорным, что вело к повышению экспрессивности выражения, и наоборот, что, соответственно, приводило к снижению экспрессивности выражения.

Эквивалентное метафорическое соответствие во всех рассмотренных случаях не выявило значитель- 
ного изменения степени экспрессивности оригинального выражения. Так, нулевая экспрессивность метафорических терминов остается нулевой или близкой к нулевой, что справедливо даже для тех выражений, в основе которых лежит яркий образ (coronae - корона, cortices - кора, mantle-мантия). Данный способ перевода представляется максимально эффективным для передачи метафорических терминов и неразвернутых устойчивых метафорических выражений в научно-популярном тексте.

При переводе оригинального метафорического выражения вариативным метафорическим соответствием на русский язык обнаруживается как сохранение общей экспрессивности выражения, так и случаи его изменения: повышение экспрессивности может происходить за счет расширения метафорического выражения (reveals - выдает ux с головой), изменения регистра (ends up - обретает пристанищзе) или за счет усиления образа посредством персонификации или уподобления явления живому существу вообще (arrived at-родивиимися). Снижение экспрессивности в подобных случаях преимущественно обусловлено заменой метафоры с ярким образом метафорой с более привычным, стертым образом (History is strewn with liars - История знает множество лжециов; bounced back - onycтилось). Данный способ перевода преимущественно эффективен. Исключение составляют случаи перевода новых выражений и новых значений уже известных выражений, поиск словарно закрепленных соответствий в ряде случаев затруднен или невозможен.

Случаи калькирования не частотны: переводчики предпочитают находить выражения и образы, привычные представителям их культуры, однако необходимость применения подобного способа перевода выражений может быть оправдана потребностью сохранить сильный образ (ocean Armageddon - океанский армагеддон; sоuр of plastic-cyn из пластмас$(b l)$, при котором в рассмотренных примерах не происходило существенного изменения экспрессивности. Избегание подобного приема объясняется стратегией приближения текста к носителям иноязычной культуры, а чрезмерное ее использование воспринимается как переводческая ошибка. Таким образом, несмотря на крайне высокий процент сохранения экспрессивности исходного выражения, данный способ перевода нельзя считать универсальным.

Сохранение оригинального образа или замена его на сходный - категории, которые в рамках данного исследования рассматривались только в случаях перевода метафоры метафорическим выражением, так как только в таком случае оказалось возможным сравнить переносимые образы, лежащие в основе выражений оригинала и перевода.
Стремление к сохранению оригинального образа преобладает, что преимущественно сочетается с отсутствием существенных изменений в экспрессивности. Усиление экспрессивности метафорического выражения в первую очередь связывается с развертыванием выражения в русском языке, что предполагает добавление элементов, эксплицирующих значение метафоры (mislead - вводить в заблуждение). В таких случаях происходит общее сохранение образа, однако отмечается его развитие. Данный способ перевода представляется крайне эффективным, однако невозможным в случае наличия особых культурных ассоциаций, связанных с метафорическим выражением, поскольку сохранение такого образа в культуре перевода приведет к непониманию метафоры и, следовательно, снижению как экспрессивности выражения, так и возможному невыполнению иллюстративной или структурной функции метафоры.

Замена образа, лежащего в основе метафоры, на сходный обусловлена стремлением переводчика сохранить уровень экспрессивности текста, для чего производится замена оригинального образа тем, что более понятен носителю культуры страны перевода, однако ряд случаев обнаруживает противоречие: образ, более близкий носителям культуры перевода, не всегда обладает степенью экспрессивности оригинала. Снижение экспрессивности связывается с заменой непривычного яркого образа на более нейтральный, стертый ([being deceitful is] woven into our very fabric - тесно связана с нашей природой, hopes skyrocketed - ожидания росли), в то время как повышение предполагает обратный процесс (implicated [in scandals] - замешанный [в скандалах], [compromise] arrived at-родивиийся [компромисс]). Таким образом, данный способ перевода является эффективным с точки зрения обеспечения понимания смысла метафоры и преимущественно сохранения ее функции, если она не является средством создания особой образности. В случае замены образа экспрессивной метафоры частотны колебания в степени экспрессивности, с равными долями случаев ее усиления и снижения. Данный способ перевода является почти столь же частотным, как и сохранение исходного образа, и потому ни один из них нельзя считать более универсальным.

Неметафорическое объяснение возможно в случае несовпадения принятых в культурах языка оригинала и перевода образных систем. Сохранение экспрессивности или ее несущественное изменение отмечается лишь в половине случаев (когда, например, оригинальное выражение представляет собой стертую метафору и не является средством выразительности: lie in ways big and small - лжем по-крупному и по мелочам, name, attached to it-рядом с ней было имя). Высок процент снижения экспрессивности выраже- 
ния, что объясняется снятием метафор, образность которых ощутима (academic science is a world largely inhabited... - среди ученых больше...). Несмотря на невысокий процент, отмечаются и случаи повышения экспрессивности выражения ([verbally] attacked [bottles]... (нейтральное выражение) - которым нынче достаются все шишки (эмоционально окрашенное выражение)). Таким образом, данный способ перевода представляется однозначно эффективным только в случаях, когда метафора не является средством создания образности.

Наиболее частотным способом перевода метафор в рассмотренных научно-популярных статьях является перевод с использованием трансформаций, обусловленных структурными несовпадениями конструкций в английском и русском языках или потребностью использовать синонимичное по значению выражение, уже закрепленное в языке перевода.

В большинстве случаев метафоры, переводимые с использованием трансформаций, сохраняют исходную экспрессивность. Сохранению экспрессивности в большей мере способствует поиск традиционного соответствия. Остальные приемы в первую очередь необходимы для экспликации семантики метафорического употребления. Ввиду значительного объема несовпадений в системах русского и английского языков на всех уровнях, трансформации являются необходимыми не только с точки зрения сохранения экспрессивности метафорических выражений, но и преимущественно выступают единственным способом сохранить смысл высказывания.

Таким образом, перевод с использованием трансформаций признается не только эффективным, но и необходимым способом перевода метафор, наблюдаемым при переводе почти половины случаев всех проанализированных метафор.

Отдельного внимания заслуживают случаи опущения метафор. В рассмотренных случаях полное опущение нечастотно, однако обнаружено во всех текстах. Преимущественно опускаются стертые метафоры, не выступающие средством создания особой образности, и потому общая экспрессивность фрагментов текста, в которых опускалась метафора, в 70 \% случаев не обнаруживала существенных изменений. Несмотря на это, опущение метафоры нельзя признать эффективным способом перевода, хотя подобный подход и оправдан в случае, если метафора трудна для восприятия или неинформативна.

При переводе текстов с русского на английский язык несколько более частотны случаи снижения экспрессивности исходного выражения. Проанализированные случаи перевода текстов с русского на английский язык позволили признать выводы в отношении эффективности разных способов, сделанные в результате анализа перевода метафор с русского на английский язык, универсальными для перевода метафор между английским и русским языком вне зависимости от направления перевода.

Эквивалентное метафорическое соответствие является более частотным, но в равной степени эффективным, способом перевода метафор, преимущественно терминов. При переводе метафор повышение экспрессивности обусловлено более яркой ощутимостью в английском языке (как в языке, из которого метафорический термин (или устойчивое выражение) был заимствован, или как в языке, сохранившем более тесную связь нового значения слова с исходным (циклическая экономика - circular economy (понятие цзикла не вызывает столь яркой визуализации круга, как прямое указание на форму (circular)), красный карлик-red dwarf (в русском языке карлик и его производные для описания людей не выделяются толковыми словарями как первые значения, в то время как первое значение слова $d w a r f$ - представитель особой расы, сходной с человеком).

Вариативное метафорическое соответствие обнаруживает увеличение процента случаев снижения экспрессивности. Здесь и далее общее увеличение числа случаев снижения экспрессивности в ряде случаев может быть объяснимо переводом текстов на неродной для переводчика язык, в результате чего наблюдается большее число нейтрализаций, например, за счет изменения регистра (иумиха - sensation, раздавать оценки - assess).

Эквивалентное неметафорическое соответствие во всех рассмотренных примерах приводило к сохранению экспрессивности исходного выражения (поскольку таким способом преимущественно осуществлялся перевод терминов или выражений с нулевой или близкой к нулевой экспрессивностью (горловина - hole).

Случаев перевода метафор с русского на английский язык вариативным неметафорическим соответствием значительно меньше, чем при переводах в обратную сторону, что может объясняться попыткой переводчика сохранить образность выражения, с целью чего происходит подбор метафорического эквивалента.

При переводе оригинальных текстов с русского на английский язык обнаружена тенденция к меньшему количеству примеров вариативного неметафорического соответствия, увеличение процента эквивалентных метафорических соответствий, а также значительное снижение объема производимых трансформаций.

При переводе научно-популярных текстов с русского на английский язык обнаруживается преимущественное сохранение оригинальной экспрессивности метафоры во всех категориях. Случаи снижения экспрессивности связаны с использованием вариа- 
тивного соответствия, неметафорического объяснения и использованием трансформаций, в особенности опущения и структурного преобразования.

Повышение экспрессивности в целом не характерно для научно-популярных текстов в обоих языках.

В заключение еще раз отметим, что метафоры широко представлены в научно-популярных текстах на английском и русском языках. Их функции неодинаковы: далеко не все метафоры являются средством создания образности и обладают экспрессивностью. Функция метафоры и яркость образа в ее основе являются важными критериями выбора способа перевода.

Наиболее распространенными способами перевода метафор с английского языка на русский и наоборот являются перевод вариативным метафорическим соответствием, а также перевод с сохранением оригинального образа (позволяющий максимально точно передать значение метафоры, что может быть необходимо для сохранения наглядности). Эффективность выбранных способов, однако, прослеживается не с учетом частотности их применения, а с учетом сохранения экспрессивности метафор, выполняющих различные функции. В результате анализа было установлено, что ни один из перечисленных способов не является универсальным, однако все при грамотной оценке функции метафоры (в первую очередь, понимании, является метафора средством создания образности или нет) позволяют сохранить экспрессивность исходных выражений и текста в целом.

\section{ЛИТЕРАТУРА}

1. Лингвистический энциклопедический словарь / под ред. В. Н. Ярцевой. М. : Большая Российская энциклопедия, 2002. 709 с.

2. Кожина М. Н., Дускаева Л. Р., Салимовский В. А. Стилистика русского языка : учебник. 4-е изд. стереотип. М. : Флинта : Наука, 2008. 464 с.

3. Позднякова Н. В. Метафора в научно-популярном стиле : автореф. дис. ... канд. филол. наук. Белгород, 1995. 14 c. URL: http://cheloveknauka.com/metafora-vnauchno-populyarnom-stile

4. Разинкина Н. М. Развитие языка английской научной литературы : лингвостилистическое исследование. М. : Наука, 1978. 210 с.

5. Маевский Н. Н. Функционирование экспрессивных средств в научно-популярных текстах // Проблемы экспрессивной стилистики. Ростов н/Д. : Изд-во РГУ, 1987. С. 7.

6. Уткина Т. И. Метафора в научно-популярном медицинском дискурсе (семиотический, когнитивно-коммуникативный, прагматический аспекты) : дис. ... канд. филол. наук. Пермь, 2006. 210 с. URL: http:// cheloveknauka.com/metafora-v-nauchno-populyarnommeditsinskom-diskurse
7. Хомутова Т. Н., Петров С. Г. Функционирование лексических средств художественной выразительности в научно-популярном тексте (на примере метафоры) // Вестник ЮУрГУ. Серия: Лингвистика. 2014. № 4. C. 45-51. URL: https://cyberleninka.ru/article/n/funktsionirovanie-leksicheskih-sredstv-hudozhestvennoy-vyrazitelnosti-v-nauchno-populyarnom-tekste-na-primeremetafory

8. Харченко B. К. Функции метафоры. Воронеж : Изд-во Воронеж. ун-та, 1992.87 с. URL: https://studfiles. net/preview/3962920/page:50/

9. Рецкер Я. И. Теория перевода и переводческая практика. М. : Международные отношения, 1974. 237 с.

10. Комиссаров В. Н. Современное переводоведение : курс лекций. М. : ЭТС, 1999. 192 с.

11. Казакова Т. А. Практические основы перевода, English $<=>$ Russian. СПб. : Союз, 2001. 320 c.

\section{REFERENCES}

1. Lingvistichesky entsyclopedichesky slovar [Linguistic encyclopedic dictionary]. Ed. by V. N. Yartseva. Moscow: Bolshaya Rossiiskaya encyclopedia, 2002. 709 p.

2. Kozhina M. N. Stilistika russkogo yazyka [Stylistics of the Russian language]. Moscow: Flinta: Nauka, 2008. $464 \mathrm{p}$.

3. Pozdnyakova N. V. Metafora v nauchno-populyarnom stile [Metaphor in popular-scientific style]. $\mathrm{PhD}$ Dissertation Abstract. Belgorod, 1995. 14 p.

4. Razinkina N. M. Razvitiye yazyka angliiskoy nauchnoy literatury [Development of English scientific prose]. Moscow: Nauka, 1978. 210 p.

5. Mayevsky N. N. Funktsionirovaniye ekspressivnykh sredstv $v$ nauchno-populyarnykh tekstakh [Functioning of language expressive means in popular scientific text]. In Problemy ekspressivnoy stilistiki. Rostov-on-Don: Rostov State University, 1987. P. 7.

6. Utkina T. I. Metafora v nauchno-populyarnom meditsynskom diskurse [Metaphor in popular scientific medical discourse]. PhD Dissertation. Perm, 2006. 210 p.

7. Khomutova T. N. Funktsionirovaniye leksicheskikh sredstv khudozhestvennoy vyrazitelnosty v naucho-populyarnom tekste [Functioning of language expressive means in popular scientific text]. In Vestnik SUSU. 2014. No. 4. Pp. 45-51.

8. Kharchenko V. K. Funktsii metafory [Functions of metaphors]. Voronezh: Voronesh State University, 1992. 87 p.

9. Retsker Y. I. Teoriya perevoda I perevodcheskaya praktika [Theory and practice of translation]. Moscow : Mezhdunarodniye Otnosheniya, 1974. 237 p.

10. Komissarov V. N. Sovremennoye perevodovedeniye [Modern translation theory]. Moscow: ETS, 1999. 192 p.

11. Kazakova T. A. Prakticheskiye osnovy perevoda [Translation techniques]. St. Petersburg: Soyuz, 2001.320 p. 
Воронежский государственный университет Яковлева И. Н., дочент кафедры перевода и профессиональной коммуникации

E-mail: yakovleva@rgph.vsu.ru

Компания Аватера

Колесникова В. С., младший менеджер отдела контроля качества

E-mail:Vkolesnikova9@yandex.ru

Поступила в редакцию 12 сентября 2019 г.

Принята к публикаџии 27 декабря 2019 г.

\section{Для цитирования:}

Яковлева И. Н., Колесникова В. С. Сохранение экспрессивности при переводе метафоры в научно-популярном тексте // Вестник Воронежского государственного университета. Серия: Лингвистика и межкультурная коммуникация. 2020. № 1. C. 41-50. DOI: https://doi. org/10.17308/lic.2020.1/2729
Voronezh State University

Yakovleva I. N., Associate Professor of the Translation and Professional Communication Department

E-mail:yakovleva@rgph.vsu.ru

Awatera Company

Kolesnikova V. S., Junior Manager of Quality Control Department

E-mail:Vkolesnikova9@yandex.ru

Received: 12 September 2019

Accepted: 27 December 2019

\section{For citation:}

Yakovleva I. N, Kolesnikova V. S. Maintianing expressivness of metaphors when translating popular-scientific text. Proceedings of Voronezh State University. Series: Linguistics and Intercultural Communication. 2020. No. 1. Pp. 41-50. DOI: https://doi.org/10.17308/lic.2020.1/2729 